\title{
Standards of care for occupational asthma
}

\author{
D Fishwick, ${ }^{1}$ C M Barber, ${ }^{1}$ L M Bradshaw, ${ }^{1}$ J Harris-Roberts, ${ }^{2}$ M Francis, ${ }^{1}$ S Naylor, ${ }^{2}$ \\ J Ayres, ${ }^{3}$ P S Burge, ${ }^{4}$ J M Corne, ${ }^{5}$ P Cullinan, ${ }^{6}$ T L Frank, ${ }^{7}$ D Hendrick, ${ }^{8} \mathrm{~J}$ Hoyle, ${ }^{9}$ \\ M Jaakkola, ${ }^{4}$ A Newman-Taylor, ${ }^{6}$ P Nicholson, ${ }^{10} \mathrm{R}$ Niven, ${ }^{11}$ A Pickering, ${ }^{11}$ R Rawbone, ${ }^{12}$ \\ C Stenton, ${ }^{8}$ C J Warburton, ${ }^{13}$ A D Curran, ${ }^{2}$ British Thoracic Society Standards of Care \\ Subcommittee Guidelines on Occupational Asthma
}

\section{See editorial on p 190 \\ - Additional data are given in the three Appendices published online only at http://thorax.bmj. com/content/vol63/issue3 \\ ${ }^{1}$ Centre for Workplace Health, Sheffield, UK; ${ }^{2}$ Centre for Workplace Health, Buxton, UK; ${ }^{3}$ University of Aberdeen, Aberdeen, UK; ${ }^{4}$ Heartlands Hospital, Birmingham, UK; \\ ${ }^{5}$ Queen's Medical Centre, Nottingham, UK; ${ }^{6}$ Royal Brompton Hospital, London, UK; ${ }^{7}$ G P Research Unit, North West Lung Centre, Manchester, UK; \\ ${ }^{8}$ Royal Victoria Infirmary, \\ Newcastle upon Tyne, UK; \\ ${ }^{9}$ North Manchester General Hospital, Manchester, UK; \\ ${ }^{10}$ BOHRF, SOM and FOM, London, UK; ${ }^{11}$ North West Lung Centre, Manchester, UK; \\ ${ }^{12}$ Health \& Safety Executive, London, UK; ${ }^{13}$ Aintree Chest Centre, University Hospital Aintree, Liverpool, UK}

Correspondence to: Dr D Fishwick, Centre for Workplace Health, Respiratory Function Unit, A Floor, Royal Hallamshire Hospital, Glossop Road, Sheffield S10 2JF, UK; d.fishwick@sheffield.ac.uk

Received 9 May 2007 Accepted 26 August 2007 Published Online First 28 September 2007
Occupational asthma remains a common disease in the UK with up to 3000 new cases diagnosed each year. The Health and Safety Executive (HSE) estimates the cost to our society to be over $£ 1.1$ billion for each 10-year period. ${ }^{1}$ In October 2001 the Health and Safety Commission agreed a package of measures aimed at reducing the incidence of asthma caused by exposure to substances in the workplace by $30 \%$ by 2010 . Key to this aim are primary prevention by proper risk assessment and exposure control, together with secondary prevention to ensure reduction in the delay between the development of allergic symptoms at work (normally nasal or respiratory) and appropriate advice to the affected worker and workplace.

Conservative estimates suggest that one in 10 cases of adult onset asthma relate directly to sensitisation in the workplace, ${ }^{2}$ with a smaller subset of workers with acute irritant induced asthma. The latter-formerly termed reactive airway dysfunction syndrome (RADS) - relates to asthma caused by exposure to high levels of airborne irritants.

The prognosis of individuals with occupational asthma is better if they are removed from exposure quickly, particularly within a year of first symptoms. ${ }^{3-5}$ However, removing individuals often leads to unemployment. If the diagnosis of occupational asthma is incorrect, advising individuals whose asthma is not caused by work to be removed from exposure may have unnecessary financial and social consequences.

- The reported incidence of occupational asthma may be underestimated by as much as $\mathbf{5 0 \%}$ (ES3* SIGN 3). (ES, Evidence Statement with original BOHRF reference number ${ }^{6}$ as suffix.)

\section{SCOPE AND BACKGROUND}

The intent of this article is not to document the entire current evidence base related to occupational asthma, as the British Occupational Health Research Foundation (BOHRF) recently completed such an evidence review. ${ }^{7}$ The key points of this article are summarised in box 1 .

This article is intended to give guidance to all healthcare professionals dealing with workers exposed to agents that potentially cause asthma, and was designed specifically for this purpose in collaboration with the British Thoracic Society (BTS) Standards of Care Committee. Mindful of the fact that managing patients in practice is very different from the way it appears in guidelines, this article serves primarily to inform readers of the recent evidence base and translate this into clinical practice.

This article is aimed to be of value to physicians and nurses based in primary and secondary care and occupational health and public health departments. It will also hopefully be useful to employers and interested workers (such as health and safety representatives).

The evidence base quoted is consistent with and normally sourced from the BOHRF guidance, although references that have been published since this guidance are cited in addition. The final version of this document has been agreed by the Standards of Care Committee and collectively produced by the Group of Occupational Respiratory Disease Specialists (GORDS), a secondary care-based group of respiratory physicians with a clinical and research interest in occupational lung disease. This group meets regularly and is coordinated by HSE.

The evidence-based ratings cited through this document relate to the original grading of evidence strength assigned by BOHRF during their evidencebased review. Evidence for each statement was graded using both the SIGN system (Scottish Intercollegiate Guidelines Network grading system) and the Royal College of General Practitioners (RCGP) three star system (1995). In the former, evidence is graded from level 1++ (high quality meta-analyses, systematic reviews of randomised controlled trials or randomised controlled trials with a very low risk of bias) to level 4 (expert opinion). In the latter, three stars denote strong evidence; two stars moderate evidence; one star limited or contradictory evidence; and no stars represent no scientific evidence.

It is not intended-nor should it be taken to imply - that this standard of care overrides existing legal obligations. Duties under the Health and Safety at Work Act 1974, the Management of Health and Safety at Work Regulations 1999, the Disability Discrimination Act 1995, the Control of Substances Hazardous to Health Regulations 2002 and other relevant legislation must be given due consideration.

This document deals primarily with asthma caused by work due to sensitisation to allergens found in the workplace.

\section{PREVENTION \\ Primary prevention}

Primary prevention of occupational asthma can be achieved by carrying out a comprehensive risk 
Box 1 Summary of major recommendations of the British Occupational Health Research Foundation (BOHRF) with revised SIGN grading levels

- The reported incidence of occupational asthma may be underestimated by as much as $50 \%$ (ES3* SIGN 3 ).

- The most frequently reported agents include isocyanates, flour and grain dust, colophony and fluxes, latex, animals, aldehydes and wood dust (ES4* SIGN 3).

- Atopy increases the risk of developing occupational asthma caused by exposure to many high molecular weight (HMW) agents that induce the production of specific $\lg E$ antibodies (ES9*** SIGN 2+).

- Occupational rhinitis and occupational asthma frequently occur as co-morbid conditions in IgE associated occupational asthma (ES12** SIGN 2+).

- The risk of developing occupational asthma is highest in the year after onset of occupational rhinitis (ES14* SIGN 2-).

- Reducing airborne exposure reduces the number of workers who become sensitised and who develop occupational asthma (ES16** SIGN 2+).

- Health surveillance can detect occupational asthma at an earlier stage of disease and the outcome is improved in workers who are included in a health surveillance programme (ES20* SIGN 3).

- Pre to post shift changes in lung function cannot be recommended for the validation or exclusion of occupational asthma (ES27* SIGN 3).

- The sensitivity and specificity of serial peak expiratory flow (PEF) measurements are high in the diagnosis of occupational asthma (ES31** SIGN 3).

- Changes in non-specific bronchial responsiveness at and away from work have only moderate sensitivity and specificity for diagnosis (ES35** SIGN 2-).

- Both skin prick and serological tests are highly sensitive for detecting specific $\lg E$ and occupational asthma caused by most HMW agents, but are not specific for diagnosing occupational asthma (ES37** SIGN 2+).

- The symptoms and functional impairment of occupational asthma caused by various agents may persist for years after avoidance of further exposure to the causative agent (ES42*** SIGN 2+).

- The likelihood of improvement or resolution of symptoms or of preventing deterioration is greater in workers who have no further exposure to the causative agent (ES43*** SIGN 2++).

- Redeployment to a low exposure area may lead to improvement or resolution of symptoms or prevent deterioration in some workers, but is not always effective (ES47* SIGN 3).

- Approximately one-third of workers with occupational asthma are unemployed up to 6 years after diagnosis (ES49** SIGN $2-1$.

- Workers with occupational asthma suffer financially (ES50** SIGN 2-).

assessment of the workplace, allowing reduction in exposure to asthmagens and through an appropriate health surveillance programme. The former will allow the identification of hazards with unacceptable risk while the latter will allow a responsible person in the workplace to identify workers at risk of allergic (or irritant) disease during pre-employment, pre-placement screening and ongoing health surveillance.

An example of primary prevention would be the reduction seen in latex-induced occupational asthma. Work with powdered latex gloves in healthcare workers was probably responsible for occupational asthma due to the aerosolisation of latex caused by opening glove containers and adding powder. Substituting these gloves with, for example, low protein nonpowdered latex gloves has been shown to reduce new cases of allergy and asthma. ${ }^{8}$

Similarly, steps to encapsulate certain workplace agents (and hence reducing the production of a dust) have also been shown to be effective at reducing workplace sensitisation. ${ }^{9}$

Exposures in the workplace should be low enough to prevent the onset of asthma in all workers, irrespective of their individual susceptibility. ${ }^{10}$ Various host factors have been shown to increase the risk of occupational asthma including genotype-for example, evidence from HLA studies has identified increased susceptibility to various agents. ${ }^{11}{ }^{12}$ These studies are of interest mechanistically, but the general area of genetic susceptibility to occupational asthma is complex and requires further research. Individual risk factors for the development of occupational asthma may therefore need to be taken into account when attempting to reduce the incidence of new cases of occupational asthma.

While these issues may need to be documented in preemployment screening for new workers, the presence of a risk factor should not be used to exclude or refuse employment, although their presence may influence the frequency of health surveillance. Furthermore, a previous history of asthma should not normally be used to exclude a worker from employment.

\section{Secondary prevention}

Secondary prevention of occupational asthma will also potentially arise as part of a health surveillance programme. In particular, once markers of early possible occupational asthma are identified, removal from exposure may lead to regression of these symptoms, preventing progression to established and disabling disease. Data exist, for example, in relation to such an approach working well in the detergent enzyme industry and for exposure to complex platinum salts. ${ }^{13}$

This approach should be backed up by a clear occupational health policy, so that there is a clear line of referral or investigation for those workers with potential allergy to workplace agents. It is likely that a proportion of these workers will need further health assessment, although the nature and location of this will depend upon local expertise

A clear example of this approach relates to the reduction in incidence of isocyanate asthma recently seen in the Province of Ontario, Canada. This followed a comprehensive programme to place under surveillance and potentially educate all diisocyanate users about the risks of isocyanate paints. Although the number of newly identified cases of occupational asthma reduced, the programme was not able to identify which component(s) of the programme had led to the observed reduction. ${ }^{14}$

\section{Tertiary prevention}

Tertiary prevention is largely concerned with reducing the disability associated with occupational asthma in workers already diagnosed with this condition. The standard advice given to such workers is that further exposure to allergens known to cause their asthma is unadvisable. If continued exposure is allowed (this decision must be taken individually 


\section{Box 2 A typical health surveillance approach for occupational asthma}

- Low level: Respiratory health surveillance when there is only suggestive evidence of a respiratory hazard, little likelihood of exposure or that the substance is normally handled in a way that prevents inhalation:

- Pre-employment enquiry and spirometry (forced expiratory volume in $1 \mathrm{~s}\left(\mathrm{FEV}_{1}\right)$ and forced vital capacity (FVC)).

- Inform workers about likely exposures and symptoms to watch out for.

- Inform workers to report such symptoms to a responsible person.

- Annual questionnaire.

- High level: Respiratory health surveillance when there is strong evidence of a hazard with associated risk of exposure:

- Pre-employment enquiry and spirometry (FEV 1 and FVC).

- Inform workers about likely exposures and symptoms to watch out for.

- Inform workers to report such symptoms to a responsible person.

- Questionnaire at 6 and 12 weeks following start of job.

- Annual questionnaire thereafter.

- Consider the use of surveillance spirometry.

- Consider the use of immunology testing.

In both instances, while the collection of data can be carried out by a responsible trained person (nurse, physician, health and safety manager, occupational health technician), it is the responsibility of a physician to interpret the data in the light of the symptoms experienced in order to give the best advice. The actual content of a health surveillance programme will additionally depend upon local factors. Workers may under-report symptoms, possibly due to the fear of losing their jobs.

All those making spirometric measures in occupational settings should have received appropriate training.

with the worker understanding the potential consequences), this must be to the lowest possible levels of allergen, and the worker must be enrolled into a "high level" health surveillance programme, as discussed below.

\section{HEALTH SURVEILLANCE}

A health surveillance programme would normally be expected in a workplace that has carried out a risk assessment (required by the Control of Substances Hazardous to Health (COSHH) regulations, ${ }^{15}$ regulation 11 , paragraph $\left.(2)(b)\right)$, which has identified a risk associated with a potential asthmagen. While the content of the programme will vary depending on local factors, HSE has produced a document ${ }^{16}$ that sets out the typical health surveillance programmes, summarised in box 2 . There are also examples of industry-specific best practice for the management and prevention of occupational asthma. ${ }^{17}$

There is limited evidence (eg, Gordon et $a^{18}$ ) to support under-reporting of symptoms in such schemes, possibly due to the fear of losing work.

- Health surveillance can detect occupational asthma at an earlier stage of disease and the outcome is improved in workers who are included in a health surveillance programme (ES20* SIGN 3).

\section{EDUCATION}

Identification of occupational asthma and workers at risk of this condition is the responsibility of all those in contact with workers exposed to agents known to cause asthma. The $\mathrm{COSHH}$ regulations state that workers exposed to allergens should be warned about symptoms that could be due to allergy. In addition, workers should be informed about how agents in the workplace can cause breathing problems and how best to avoid symptoms, and particularly doing so by reducing exposure to asthmagens. It should also be made clear to workers what to do, and to whom they should speak at each workplace, should they develop such symptoms, particularly if these occur between scheduled health surveillance visits.

Educational programmes should be aimed not only at employers but at a variety of healthcare professionals including nurses and doctors (based in industry, primary and secondary care), occupational hygienists and workers with responsibility for health and safety.

The health surveillance programme should include an element of continuing education, although this does not have to be delivered at the same time as the standard surveillance. Indeed, worker education could be included as a separate component of work activity. The key components of such a programme that should be delivered locally using best available resources are shown in box 3 . The HSE website on occupational asthma (www.hse.gov.uk/asthma/index.htm) acts as an excellent resource.

An example of a worker/patient information sheet is given in Appendix 3 available as an online supplement.

\section{DIAGNOSTIC PROCESS}

The diagnosis of occupational asthma may be relatively straightforward, but may also pose certain problems. The process is normally iterative, requiring time and access to key resources including nursing skills and lung function tests.

\section{The patient journey}

Figure 1 shows the typical patient journey, moving from a period of exposure while asymptomatic to a final diagnosis. Little is currently known about the delays experienced at each of these steps. In addition, workers have to recognise that respiratory symptoms may relate to work, a process that will depend in part on adequate education about this potential link. While the BOHRF guidelines suggest that education should occur, limited UK data suggest that this does not happen consistently. ${ }^{19}$

Similarly, feedback to the workplace following a diagnosis of occupational asthma, in order to effect appropriate change, is probably variable. While employers have a responsibility to report known cases of occupational asthma to HSE under the Reporting of Injuries, Diseases and Dangerous Occurrences Regulations, 1995 (RIDDOR, http://www.riddor.gov.uk/), ${ }^{20}$ this may not happen in practice. Clearly, employers need to be aware that a case of occupational asthma has been diagnosed in their workforce, but practically this information may not be disclosed to the employer, particularly if the worker has not given consent. Contractually, however, if a worker needs annual certification of fitness to work in an area where there are allergens, the health practitioner could withhold a certificate of fitness where occupational asthma is suspected.

All workers with possible asthma, new onset asthma, worsening control of existing asthma or airways obstruction should be suspected of having occupational asthma. In addition, 
Box 3 Content of an educational programme for occupational asthma should revolve around these key statements

- 1 in 10 cases of adult onset asthma potentially relate to work.

- There are many causes of occupational asthma, although the top 10 agents are probably responsible for most cases in the UK. Individual causes need to be discussed in detail.

- Work-related respiratory symptoms (cough, wheeze, chest tightness, shortness of breath) are key to a diagnosis, including nasal and eye symptoms as a possible early marker of allergic disease.

- Spotting cases (and those at risk) early is important in the workplace, as well as primary and secondary care.

- The outlook is better when workers are removed early from harmful exposure.

- Baseline investigations are easy to perform and should include history taking, lung function measures ( $\mathrm{FEV}_{1}$ and $\left.\mathrm{FVC}, \mathrm{PEF}\right)$ and serial PEF measures.

- OASYS II software (or other PEF automated software) should be used to analyse serial PEF.

- The indications for referral to a specialist centre would include advice on existing investigations, measures of bronchial responsiveness, immunological investigations and challenge tests (specific and non-specific).

- A confirmed diagnosis has implications for the affected worker (financial and psychosocial), co-workers (both exposed and atrisk) and the workplace (requires intervention to reduce exposure).

- Health surveillance is an important way of identifying those with early symptoms and signs of allergy.

- Every effort must be made to re-deploy those with a diagnosis of occupational asthma to reduce the financial impact of this condition.

- The diagnosis of occupational asthma has legal ramifications.

- Compensation for occupational asthma may be available from Industrial Injuries Benefit.

- Compensation for occupational asthma may be available following a civil (common law) legal action.

there may be merit in investigating patients who intend to return into the workplace but are currently not at work due to respiratory ill health. All patients therefore must be asked about work in relation to their respiratory, nasal and eye symptoms, as failure to do so could lead to a missed diagnosis of occupational asthma or allergy.

A decision must be made locally as to the extent of investigation prior to possible referral for specialist advice. In practice, medical history, physical examination, spirometry, serial PEF with a computerised software analysis, chest radiography, immunology and bronchial responsiveness assessment may be carried out in non-specialist centres or by early referral to a specialist centre.

Recent data from a BTS study suggest that, while secondary care-based respiratory departments without a specialist declared interest in occupational lung disease have a certain diagnostic capability, access to computerised serial PEF analysis and measures of airway responsiveness are more fragmented across the UK. ${ }^{21}$ For example, only $12 \%$ of selected secondary care facilities currently had access to OASYS style PEF software analysis and $41 \%$ to non-specific bronchial responsiveness measures.

\section{Medical history}

Figure 2 shows a typical algorithm for assessment of occupational asthma and Appendix 1 (available as an online supplement) shows a typical proforma that could be used to record all relevant clinical information.

Medical history taking is the key to making a diagnosis of occupational asthma, as the presence of work-related nasal or respiratory symptoms is a central feature of occupational rhinitis and asthma. Occupational respiratory history taking is time consuming, and most new patients require up to $1 \mathrm{~h}$ for their first assessment. All respiratory symptoms should be recorded and the significance of work-related wheeze, chest tightness, cough, phlegm production and shortness of breath should be treated with equal concern.

History taking and questionnaire responses are sensitive indicators of asthma ${ }^{22-24}$ but are non-specific, implying that there are substantial proportions of workers who complain of work-related respiratory symptoms who do not have occupational asthma or evidence of workplace sensitisation. ${ }^{25}$

A period of time between first exposure to a putative agent and the development of work-related respiratory symptoms (the latent period) is recognised as a typical feature of occupational asthma. The duration of the latent period can be as short as a few months (or weeks in rare instances ${ }^{26}$ ), or extend for many years, ${ }^{27}$ and is seen, for example, in asthma due to flour dust exposure. ${ }^{28} 29$ Sensitisation and occupational asthma are most likely, however, to develop in the first 2 years of exposure for most agents.

Allergic nasal symptoms are important and should be treated seriously in exposed workers. Limited evidence suggests that the risk for occupational asthma is increased in those with workrelated allergic rhinitis, ${ }^{30}{ }^{31}$ and that this risk is highest in the first 12 months of exposure. Those with work-related rhinitis should be enrolled into a high-level health surveillance programme and consideration given to immunological testing (normally either skin prick testing or specific IgE testing) where appropriate. $^{6}$

- Occupational rhinitis and occupational asthma frequently occur as co-morbid conditions in IgE associated occupational asthma (ES12** SIGN 2+).

\section{Occupational history}

A detailed occupational history should also be taken and is essential to the diagnostic process. ${ }^{32}$ All potential jobs and job tasks should be listed, along with potential and known exposures. Workers should be allowed to talk freely about their jobs and workplace. The list of potential occupational agents that can cause occupational asthma is long and is constantly updated. The HSE publication "Asthmagen?" intermittently updates common causes (www.hse.gov.uk/asthma/asthmagen. pdf) and Appendix 2 (available as an online supplement) lists the current agents identified.

- The most frequently reported agents include isocyanates, flour and grain dust, colophony and fluxes, latex, animals, aldehydes and wood dust (ES4* SIGN 3).

- The risk of developing occupational asthma is highest in the year after onset of occupational rhinitis (ES14* SIGN 2-).

\section{Investigations}

This section briefly catalogues the important and relevant investigations for occupational asthma. Investigations are generally mandatory to confirm or exclude occupational asthma 


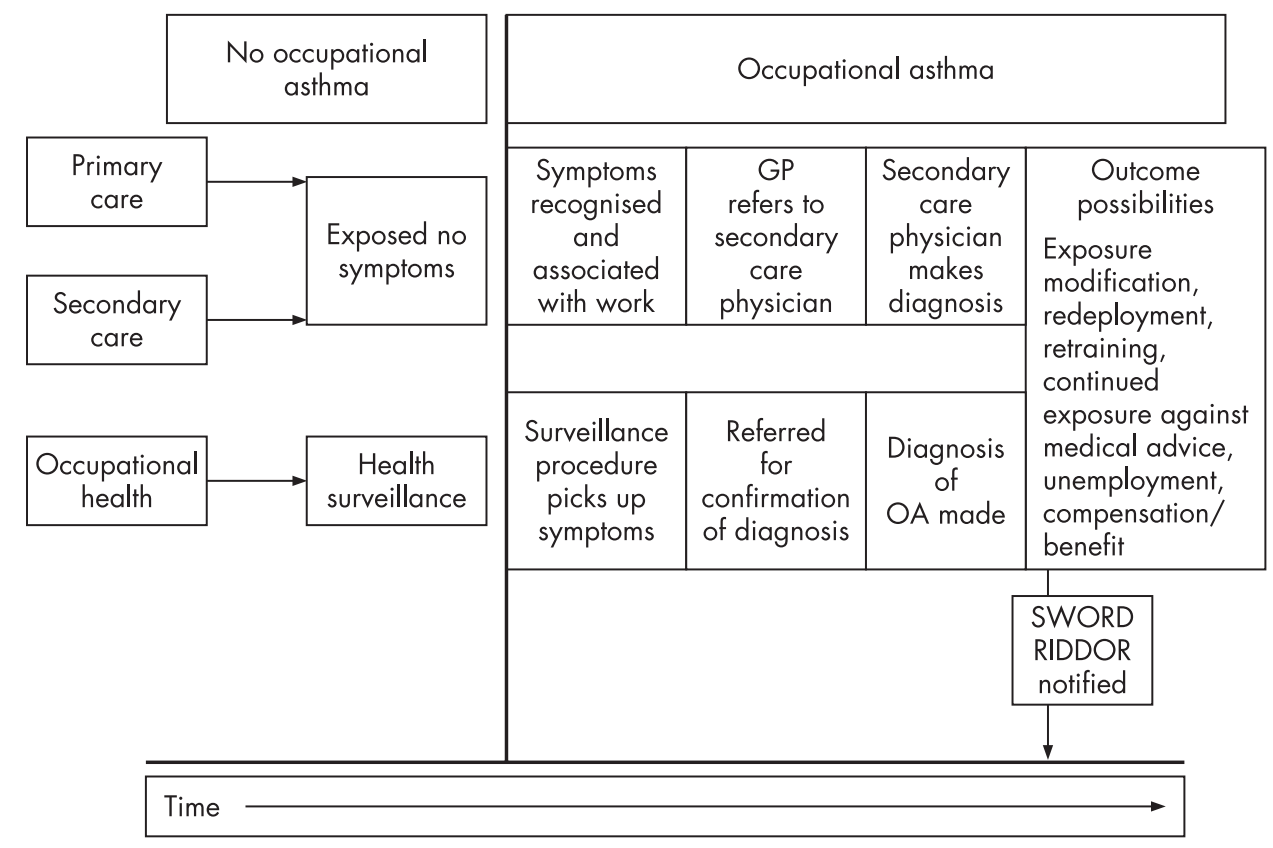

Figure 1 The patient journey. OA, occupational asthma; SWORD, Surveillance of Work-Related Occupational Respiratory Disease Schemes; RIDDOR, Reporting of Injuries, Diseases and Dangerous Occurrences Regulations.

in exposed symptomatic workers currently in the workplace, or those who have abnormal results identified as part of a regular health surveillance programme. A recent UK-based Delphi exercise has identified a list of investigations, and prioritised these for importance when assessing possible occupational asthma. ${ }^{33}$ Table 2 summarises this requirement.

\section{Lung function}

All suspected cases of occupational asthma should have $\mathrm{FEV}_{1}$ and FVC measured according to agreed criteria. For example, the Association of Respiratory Technologists and Physiologists (ARTP; www.artp.org.uk) produces standards and offers training for spirometric assessment. The recent European Respiratory Society (ERS) spirometry standardisation document is a useful guide. ${ }^{34}$ Comparison must always be made with a predicted value and the worker's previous lung function if available.

The use of significant bronchodilator response (15\% improvement in $\mathrm{FEV}_{1}$ and at least $200 \mathrm{ml}$ ) to help make a diagnosis of asthma should be consistent with existing BTS asthma guidance (summarised at www.brit-thoracic.org.uk/). Such measures may help to distinguish between asthma and chronic obstructive pulmonary disease (COPD), although clearly workers with smoking-related COPD may also develop occupational asthma. The role of other guidance is important here, with particular relevance to oral or inhaled steroid trials.

Pre- and post-shift measures of $\mathrm{FEV}_{1}$ are not generally helpful to either confirm or refute a diagnosis of occupational asthma.

\section{- Pre- to post-shift changes in lung function cannot be recommended for the validation or exclusion of occupational asthma (ES27* SIGN 3).}

\section{Serial peak expiratory flow}

Serial peak expiratory flow (PEF) measures are an important investigation when occupational asthma is suspected and have a considerable evidence base. ${ }^{35-38}$ With appropriate training and explanation, it is possible to achieve high quality recordings in workers suspected of asthma. ${ }^{39}$ While they are subject to potential falsification and inaccurate transcription, they offer the best and easiest first-line approach to assessing the physiological response to inhaled agents in the workplace. BOHRF guidance suggests that it is possible to obtain high quality chart recordings from over $70 \%$ of patients.

PEF should be recorded at least four times a day for four continuous weeks in the first instance. It is best to aim for 2hourly readings, so that practically at least four good measures per day will be achieved. ${ }^{40}$ Suitable record forms can be downloaded from www.occupationalasthma.com, www.hsl. gov.uk/cwh/ or www.scottishshield.org. Ideally, inhaled steroids should be withheld until serial PEF measurements are complete. If inhaled medication is required during these investigations, doses should be kept constant and as low as possible to control symptoms.

If the worker is currently not exposed, a 2-week run-in period can be assessed during a period of no workplace exposure followed by a return to work. All recordings should be written on a standard proforma and then entered into suitable software for PEF analysis. This has two main advantages: first, the data are presented graphically, allowing ease of interpretation and second, this allows easier recognition of patterns of PEF between work and rest. At least one software package ${ }^{41}$ calculates a work effect index from a discriminant analysis based on pattern recognition. Such analysis allows PEF charts to be graded as positive, equivocal or negative for a diagnosis of occupational asthma. A positive PEF chart (work effect index $\geqslant 2.5$ ) has a quoted sensitivity of approximately $75 \%$ and a specificity of $95 \% .{ }^{38}$ However, the positive and negative predictive values for a result from a chart vary according to the prevalence of occupational asthma in the population studied. Any problems with interpretation of PEF charts should be referred to a specialist centre used to analysing and interpreting these charts. While serial PEF charts document a physiological work effect, they do not confirm a specific cause for this. Portable logging devices are available to measure serial lung function over time, including measures of $\mathrm{FEV}_{1}$. At present 


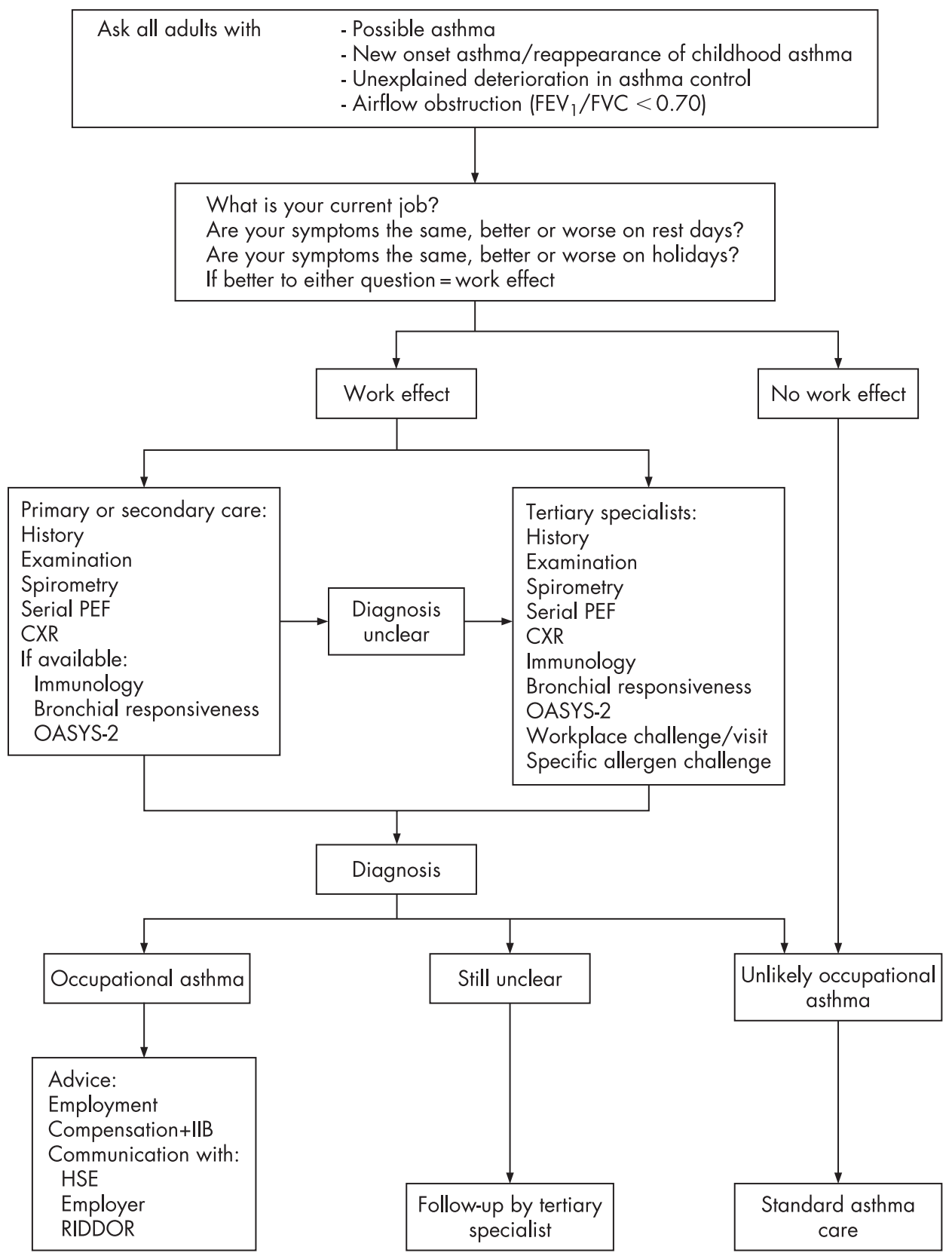

Figure 2 Assessment of patients with possible occupational asthma. FEV 1 , forced expiratory volume in 1 s; FVC, forced vital capacity; PEF, peak expiratory flow; CXR, chest radiography; IIB, Industrial Injuries Benefit; HSE, Health \& Safety Executive; RIDDOR, Reporting of Injuries, Diseases and Dangerous Occurrences Regulations.

there is little evidence to recommend these over standard PEF meters.

- The sensitivity and specificity of serial peak expiratory flow (PEF) measurements are high in the diagnosis of occupational asthma (ES31** SIGN 3).

\section{Immunological testing}

Testing for an immunological response to inhaled agents may be carried out as part of a high level health surveillance programme or as part of the clinical investigation in a hospital setting.

Skin prick testing to common aeroallergens (typically house dust mite, grass pollen and cat) may be carried out to define atopic status. While atopy may increase the risk of developing sensitisation to other (including occupational) aeroallergens, its presence should not be used to exclude workers from employment. Atopy increases the risk of developing occupational asthma caused by exposure to many high molecular weight agents. ${ }^{42-47}$

Specific IgE can be measured to common aeroallergens and also to certain occupational allergens. Some of these tests are commercially available (such as flour, latex, storage mites and some crustaceans) and some are available in specialised laboratories such as the Health and Safety Laboratory (www. hsl.gov.uk/) or the Occupational and Environmental Lung Disease Unit at the Royal Brompton Hospital NHS Trust (www2.rbht.nhs.uk/services/respmed/). Both these laboratories have tests available to a wide range of allergens including laboratory animal urine antigens, acid anhydrides, enzymes, reactive anhydride dyes, arthropods, seafoods and certain drugs. Skin prick testing is preferable for complex platinum salts as there is no validated in vitro test. 
Table 2 Facilities for assessing cases of occupational lung disease

\begin{tabular}{|c|c|c|}
\hline Rating & $\begin{array}{l}\text { Median } \\
\text { panel } \\
\text { score }\end{array}$ & Facility \\
\hline \multirow[t]{2}{*}{ Absolute necessity in all patients } & 9 & Pre-bronchodilator $\mathrm{FEV}_{1}$ as a percent of predicted \\
\hline & & Pre-bronchodilator FVC as a percent of predicted \\
\hline \multirow[t]{4}{*}{ Facility must be available } & 8 & Peak flow monitoring and plotting of results \\
\hline & & OASYS 2 analysis of peak flow records \\
\hline & & Non-specific provocation challenge in the laboratory \\
\hline & & Specific $\lg E$ to a wide variety of occupational allergens \\
\hline \multirow[t]{12}{*}{ Facility must be available } & 7 & Carbon monoxide transfer factor (TLCo) \\
\hline & & Transfer coefficient (Kco) \\
\hline & & Non-specific challenge serially at work and away from work \\
\hline & & Specific occupational challenge in the clinical laboratory \\
\hline & & Chest radiography \\
\hline & & Total $\lg E$ \\
\hline & & Skin prick testing to common environmental allergens \\
\hline & & Workplace visit by a clinician \\
\hline & & Workplace challenge with peak flow monitoring/spirometry \\
\hline & & $\begin{array}{l}\text { Standard haematology/biochemistry (FBC, U\&E, liver function, } \\
\text { thyroid function, calcium) }\end{array}$ \\
\hline & & Access to a toxicology database \\
\hline & & Specific lgE testing to common environmental allergens \\
\hline \multirow[t]{6}{*}{ May be useful but not a necessity } & $6-4$ & Measurement of workplace exposure levels \\
\hline & & Assessment of vocal cord dysfunction \\
\hline & & Portable lung function logging device \\
\hline & & Standardised occupational history form \\
\hline & & Training in occupational medicine to at least Dip Occ Med \\
\hline & & Total lung capacity \\
\hline Not routinely required & 3 & Sputum eosinophils \\
\hline \multirow[t]{3}{*}{ Not routinely required } & 2 & Exhaled nitric oxide \\
\hline & & Expired carbon monoxide \\
\hline & & Exhaled breath condensate for analysis of inflammatory markers \\
\hline
\end{tabular}

Specific IgE testing can also be measured to actual material taken from the workplace, normally as part of a specialised investigation of a workplace or a research study. The presence of specific IgE to workplace allergens identifies sensitisation to the relevant allergen but does not necessarily identify any disease related to this. For example, certain bakers have evidence of specific IgE to wheat flour in the absence of work-related (or indeed any) respiratory or nasal symptoms. ${ }^{48} 49$ The test is therefore not totally specific for occupational asthma and is likely to vary individually between agents.

Specific IgE is not always present in workers (flour and enzyme exposed bakers again serve as a good example) with a confirmed diagnosis of occupational asthma physiologically, and therefore the presence of specific IgE to a workplace allergen in this context is not fully sensitive. Nevertheless, in the presence of identified asthma or rhinitis, a positive IgE to a well characterised occupational allergen can be taken as evidence of an occupational cause when supported by the presence of other clinical features such as work-related symptoms.

While there is large variation between allergen types, specific IgE testing is much more useful in workers exposed to high molecular weight and especially proteinaceous allergens. Groups of allergens where specific IgE testing may be useful include the following: laboratory animal products, flour, enzymes, acid anhydrides, insects, seafoods, certain laxatives and plant products such as latex and woods.
Specific IgE to low molecular weight agents is technically much more difficult to measure and interpret, and a diagnosis of occupational asthma in such cases must not depend on IgE findings. Carrying out and interpreting specific IgE to low molecular weight agents is an area for specialist referral and opinion. Sensitisation to low molecular weight agents is also likely to involve non-IgE mediated mechanisms.

- Atopy increases the risk of developing occupational asthma caused by exposure to many high molecular weight agents that induce the production of specific IgE antibodies (ES9*** SIGN 2+).

- Both skin prick and serological tests are highly sensitive for detecting specific IgE and occupational asthma caused by most high molecular weight agents, but are not specific for diagnosing occupational asthma (ES37** SIGN 2+).

\section{Non-specific airway responsiveness}

Measures of airway responsiveness to non-specific agents (eg, histamine, methacholine, cold air) are a useful diagnostic investigation for those with occupational asthma. ${ }^{50}$

Single measures of responsiveness are usually carried out in a respiratory function laboratory, although they can be carried out in the workplace. ${ }^{51}$ The interpretation of airway hyperresponsiveness is confounded by the differing measurement techniques used. A normal result from a test of airway reactivity 
is not sufficiently useful to exclude occupational asthma as this may be normal in $5-40 \%$ of specific challenge positive workers. The BOHRF guidelines suggest that while single measures of airway responsiveness may be useful and its presence increases the likelihood of asthma, the absence of this does not exclude occupational asthma. ${ }^{52} 53$

Multiple or sequential measures of airway responsiveness are also used when investigating occupational asthma, and are possible to achieve in the outpatient setting. ${ }^{545}$ These tests require measures to be made during periods of work and periods of rest. Access to a relevant (normally specialist) respiratory centre is needed. The hypothesis underlying these measures is that, if asthma control and symptoms are less good during periods of exposure at work to allergens, there will be an associated change (more responsive) in airway responsiveness compared with that measured during periods of rest or nonexposure. Sequential measures of airway responsiveness demonstrate sensitivities of $48-67 \%$ and specificities of $54-78 \%$ for occupational asthma, depending on the definitions used of significant change.

- Changes in non-specific bronchial responsiveness at and away from work have only moderate sensitivity and specificity for diagnosis (ES35** SIGN 2-).

\section{Specific challenge testing}

These should be carried out only in specialised (tertiary) centres. A positive test identifies the cause of occupational asthma, provided exposures received are equivalent to those in the workplace. Negative tests do not necessarily exclude occupational asthma as the challenge may not adequately reproduce the full extent of the exposures in the workplace. ${ }^{56-58}$ Exposure received during specific challenges should be measured where practical.

Alternatively, a workplace challenge may be used (a variation of serial PEF assessment). This usually involves frequent monitoring of airway physiology (normally $\mathrm{FEV}_{1}$ or PEF) on multiple days of work during periods of exposure and nonexposure to the agents thought responsible for causing respiratory symptoms. One way of approaching this type of challenge is to take data from non-exposed days to calculate a mean and 95\% confidence interval (CI) of the "expected" $\mathrm{FEV}_{1}$ at each time point. These are then used to compare with the $\mathrm{FEV}_{1}$ values measured on exposed days. ${ }^{59}$

\section{Other techniques}

Newer techniques are available to investigate potential cases of occupational asthma but are best confined currently to research. These include dynamic estimates of cellular response (based on flow cytometry and cytokine profiling of blood, bronchoalveolar lavage and sputum, exhaled nitric oxide measurement and induced sputum).

\section{MEDICAL MANAGEMENT}

The management of occupational asthma does not differ significantly from the management of asthma that is not work related (summarised by the BTS at www.brit-thoracic.org.uk/). Treatment with inhaled steroids is likely to reduce the diagnostic sensitivity of investigations, and hence it is reasonable to withhold these where possible until the diagnosis is clarified.

Once the diagnosis of occupational asthma has been made, this information should be given specifically (preferably in writing) to the patient who should be advised that the prognosis is improved by early complete removal from exposure. The best way of doing this is to remove the cause from the workplace (for instance, glutaraldehyde from cold sterilisation).

Occupational asthma may develop into a chronic condition, similar to non-occupational asthma, and may require similar intervention with asthma medication.

Communicating with the workplace for those healthcare workers based in primary and secondary care is useful but requires the patient's written consent. If a worker refuses consent to communicate with the workplace, this should be respected. Patients should be warned of the possible adverse affects on their lungs, and that they are potentially placing coworkers at risk by not permitting the necessary workplace investigations.

Boxes 4 and 5 summarise (respectively) advice for primary care, secondary care and occupational health-based professionals.

- The symptoms and functional impairment of occupational asthma caused by various agents may persist for years after avoidance of further exposure to the causative agent (ES42*** SIGN 2+).

- The likelihood of improvement or resolution of symptoms or of preventing deterioration is greater in workers who have no further exposure to the causative agent (ES43*** SIGN 2++).

\section{CASE MANAGEMENT}

\section{Rehabilitation and redeployment}

Ideally, affected workers should be redeployed within the same workplace (in a non-exposed task) in order to minimise the consequences discussed below. In practice this rarely happens, and many remain exposed or have their employment terminated. Nevertheless, all healthcare workers responsible for such workers (or patients) should consider possible redeployment within the same worksite following suitable alterations to the workplace.

- Redeployment to a low exposure area may lead to improvement or resolution of symptoms or prevent deterioration in some workers but is not always effective (ES47* SIGN 3).

\section{Communication and ethical issues}

These are notoriously difficult areas and overlap with the medicolegal consequences of disease. However, certain basic principles operate.

Individuals have a right to confidentiality within a medical consultation and series of investigations. If a patient consents to the disclosure of information, written information should be shared with his/her employer and, if necessary, with the HSE. The reasons for doing this are many but include the following: (1) employers have a duty to report cases of occupational asthma under the RIDDOR scheme but cannot do so if they are unaware of the index case; (2) if one worker in an exposed workforce has developed occupational asthma, others may be at risk.

\section{Compensation}

The patient should also be told of the possibilities for compensation and, specifically, the two main options available to them. First, they should be given advice about the Benefits Agency Compensation Scheme for Occupational Asthma and helped with this. More information can be found at www.dwp. gov.uk/advisers/claimforms. Second, they should be given 
- At least 1 in 10 of all adult onset asthma relates to occupational exposure.

- All healthcare workers should ask patients with airways disease about their current and previous work.

- All such patients should be asked about the nature of the agents with which they work. Patients should be allowed to describe these agents and their workplace conditions in their own words.

- All patients with respiratory symptoms who currently work should be asked about the work relationship of their symptoms (if any), in a neutral tone.

- A suggested wording for these questions is as follows: "Is your (wheeze/chest tightness/shortness of breath/nasal irritation) the same, better or worse on your rest days/ holidays?"

- The outlook for occupational asthma is better if workers are removed earlier from exposure. All steps in the patient's journey contribute to potential delay.

- Make early referrals to a specialist with an interest in occupational asthma if such a diagnosis is suspected.

- All workers currently exposed to agents that can cause asthma and have work-related respiratory symptoms should undergo serial PEF measures. This can be initiated in primary care or in the occupational health setting, in addition to secondary care. Local expertise is likely to influence the local decision to investigate.

- A diagnosis of occupational asthma should never be based on history alone, and all reasonable attempts must be made to carry out objective tests.

- The pharmacological treatment of asthma is identical to that of non-occupational asthma. All physicians treating cases should not underestimate their power to prevent further cases by appropriate communication with legislators and workplaces, and by involvement in local education programmes (see box $3)$.

- The index case of occupational asthma should not have further harmful exposure to the likely causative agent or process, and should prompt a full assessment of potential workplace exposures.

advice about a potential civil claim. In particular, patients should be told that if a civil claim is anticipated, a time limit might apply following the date of knowledge (the date the individual became aware that their asthma was occupational in origin) beyond which it is not possible to commence a claim. This time period is usually 3 years in England. There are regional UK differences in civil law and it is appropriate to tell patients to take advice from a personal injury lawyer if they are contemplating legal action.

\section{Disability Discrimination Act 1995 (amended 2005)}

This Act protects the rights of workers with various forms of disability. The legislation is complex, but effectively protects a disabled person in the workplace thought to be at a "substantial disadvantage in comparison with persons who are not disabled". This may mean that employers have to make one or more suitable adjustments for those with asthma. The Act may also apply to workers who have developed medical problems (such as asthma) directly as a result of workplace exposures.
- All responsible people in the workplace and all relevant occupational health professionals should be aware of the large number of agents known to cause occupational asthma.

- The greater the level of exposure to agents that cause asthma, the greater the risk to the worker.

- Pre-employment screening may help to identify those at greater risk of occupational asthma, but the use of poorly discriminating factors such as atopy and smoking should not be used to actively exclude potential workers.

- Those workers with an established diagnosis of occupational asthma to a known agent should not be exposed to this agent again, and should be given this advice at any potential new job application.

- Workplaces should actively seek to remove or substitute agents known to cause asthma wherever possible, or reduce exposure where not possible.

- If respiratory protection is being used, it must be used correctly following a fit test.

- Employers should tell all workers about the use of agents that can cause asthma, and that all workers should report symptoms (respiratory, nasal) to a responsible person.

- Health surveillance should be carried out using regular questionnaires. Lung function and allergy tests (skin and blood tests) should be used where appropriate. The HSE MS25 publication deals with this in more detail.

- The frequency of health surveillance should be at least yearly and more often in the first 2 years of employment as the risk of developing occupational allergy is greatest during the early years of exposure.

- Health surveillance should be more frequent when a worker develops nasal symptoms suggestive of rhinitis or rhinoconjunctivitis or has asthma when first employed.

- An established case of occupational asthma or occupational rhinitis should prompt a full assessment of likely exposures in the workplace and the workplaces changed where appropriate to reduce the risk to other workers. The index case of occupational asthma should not have further harmful exposure to the likely causative agent or process.

\section{WORKPLACE INTERVENTION}

\section{Exposure control}

Risk assessment in the workplace is designed to minimise workplace risk associated with various hazards. This process will normally occur as part of a Control Of Substances Hazardous to Health (COSHH) assessment, further details of which can be found on the HSE website (www.hse.gov.uk/) or from COSHH essentials (www.coshh-essentials.org.uk/).

Fundamental to this process is identifying all potential inhaled hazards and assessing the associated risk in that particular workplace. For example, isocyanate spray paints are hazardous when inhaled but probably pose little risk when in solution form (with the exception of risk of skin sensitisaton ${ }^{60}$ ) prior to activation. It is the act of mixing these chemicals with an activator and aerosolising these when spraying that is associated with a significant risk.

While it is beyond the scope of this article to deal with these issues in detail, the principles of occupational hygiene should be adhered to. In principle, this involves substituting harmful exposures where possible, and if not possible extracting by the 
use of local exhaust ventilation. Furthermore, process alteration and relocation may have an important role.

Only when these measures are not possible should respiratory protection be used. In other words, the use of respiratory protection should be thought of as a "last resort" when other control measures fail. If respiratory protection is used, "fit testing" is available to ensure that the worker is adequately protected.

- Reducing airborne exposure reduces the number of workers who become sensitised and who develop occupational asthma (ES16** SIGN 2+).

\section{Psychosocial}

Workplaces have complex social and psychological dynamics. The identification of possible cases of occupational asthma and their subsequent management must take these into account. For example, there are limited qualitative data ${ }^{61}$ that suggest that workplace alteration alone will not always lead to the appropriate change in behaviour required to reduce risk to workers. Also, workers may not perceive workplace risks if the disease or condition associated with exposure is of long latency. Recent HSE strategy has been to include case histories of affected patients on video in workplace education (for example, in the motor vehicle industry and baking industry) to make the visual impact and enforce the point that occupational asthma can ruin normal lives.

Again, peer pressure from co-workers (both positive and negative) is likely to be important in determining behaviours and compliance with workplace regulation. As a consequence, it is essential to involve all staff, unions and health and safety advisors in all such decisions.

Once workers develop symptoms suggestive of occupational asthma, it is important that these are recognised to be related to work and not misattributed to non-work related causes. Many will fear the economic ramifications of such a diagnosis. This appears to represent a significant barrier to early diagnosis and an "honest" contribution to health surveillance. These problems are compounded by limited redeployment and retraining opportunities within the workplace and consequently poor employment prospects.

From the employer's point of view, some fear having to meet the costs associated with a case of occupational asthma including sickness costs, absenteeism, potential compensation claims and increased liability insurance. Rather than acting as an incentive for encouraging preventive measures, the compensation system could reduce reporting of occupational asthma by both employers and employees.

A recent HSE funded project to assess the costs of occupational asthma concluded that the majority of costs were borne by the affected worker and the Government (www.hse. gov.uk/research/rrpdf/rr474.pdf).

- Approximately one-third of workers with occupational asthma are unemployed up to 6 years after diagnosis (ES49** SIGN 2-).

- Workers with occupational asthma suffer financially (ES50** SIGN 2-).

\section{AUDIT TOOL}

All patients with suspected occupational asthma should have the following clearly documented in the medical case notes by the second consultation:

- A full list of occupations held and likely associated occupational exposures.
- $\mathrm{FEV}_{1}$ and FVC.

- If at work, serial PEF measures taken for at least four continuous weeks including rest days with at least four good quality readings per day analysed by a validated method.

- If exposed to allergen with appropriate specific IgE measure or skin prick test, the result of this test.

- Letter to patient concerning advice about continuing employment once a diagnosis has been made.

- Compensation advice appropriate to the case.

\section{FUTURE DEVELOPMENTS}

The evidence base continues to grow in relation to occupational asthma. Current areas of particular interest include novel agents, mechanisms of sensitisation and the health effects associated with complex multiple exposures. In addition, the diagnostic process in occupational asthma and choice of the most appropriate investigations is the subject of current debate.

Acknowledgements: The authors acknowledge the help of Dr Helen Smith and Dr John Osman for their helpful input, and the British Occupational Health Research Foundation.

Funding: The standard of care was produced within the GORDS groups, the meetings of which are supported by the Health and Safety Executive of the UK.

Competing interests: None.

\section{REFERENCES}

1. Health and Safety Executive. Asthma. 2006. http://www.hse.gov.uk/asthma/ index.htm.

2. Blanc PD, Toren K. How much adult asthma can be attributed to occupational factors? Am J Respir Crit Care Med 1999;107:580-7

3. Burge PS. Non-specific bronchial hyper-reactivity in workers exposed to toluene diisocyanate, diphenyl methane di-isocyanate and colophony. Eur J Respir Dis 1982:123:91-6.

4. Chan-Yeung M, Maclean L, Paggiaro PL. Follow-up study of 232 patients with occupational asthma caused by western red cedar (Thuja plicata). J Allergy Clin Immunol 1987;79:792-6.

5. Tarlo SM, Banks D, Liss G, et al. Outcome determinants for isocyanate induced occupational asthma among compensation claimants. Occup Environ Med 1997:54:756-61.

6. Nicholson PJ, Cullinan P, Newman Taylor AJ, et al. Evidence based guidelines for the prevention, identification, and management of occupational asthma. Occup Environ Med 2005;62:290-9.

7. British Occupational Health Research Foundation (BOHRF). Occupational asthma: identification, management and prevention: evidence based review and guideline. http://www.bohrf.org.uk/content/asthma/html.

8. Latza U, Haamann F, Baur X. Effectiveness of a nationwide interdisciplinary preventive programme for latex allergy. Int Arch Occup Environ Health 2005;78:394402.

9. Sarlo K. Control of occupational asthma and allergy in the detergent industry. Ann Allergy Asthma Immunol 2003:90(5 Suppl 2):32-4.

10. Rawbone RG. Future impact of genetic screening in occupational and environmental medicine. Occup Environ Med 1999;56:721-4.

11. Mapp CE, Fryer AA, De-Marzo N, et al. Glutathione S-transferase GSTP1 is a susceptibility gene for occupational asthma induced by isocyanates. J Allergy Clin Immunol 2002;109:867-72.

12. Mapp CE, Beghe B, Balboni A, et al. Association between HLA genes and susceptibility to toluene di-isocyanate-induced asthma. Clin Exp Allergy 2000; 30:651-6.

13. Merget R, Caspari C, Dierkes-Globisch A, et al. Effectiveness of a medical surveillance program for the prevention of occupational asthma caused by platinum salts: a nested case-control study. J Allergy Clin Immunol 2001;107:707-12.

14. Tarlo SM, Liss GM, Yeung KS. Changes in rates and severity of compensation claims for asthma due to diisocyanates: a possible effect of medical surveillance measures. Occup Environ Med 2002;59:58-62.

15. Health and Safety Executive. Control of Substances Hazardous to Health (COSHH) regulations. London: HSE HMSO Books, 2001.

16. Health and Safety Executive. Medical aspects of occupational asthma. MS25 London: HSE HMSO Books, 2001.

17. Nicholson $\mathbf{P}$, Newman Taylor AJ, Oliver $\mathrm{P}$, et al. Current best practice for the health surveillance of enzyme workers in the soap and detergent industry. Occup Med 2001; 51:81-92.

18. Gordon SB, Curran AD, Murphy J, et al. Screening questionnaires for bakers asthma: are they worth the effort? Occup Med (Lond) 1997;47:361-6.

19. Barber C, Fishwick D, Naylor S, et al. Control measures and training provision in UK bakeries (abstract). SOM Annual Scientific Meeting, 2006. 
20. Health and Safety Executive. RIDDOR. 2006. http://www.hse.gov.uk/riddor

21. Naylor S, Elms J, Curran AD, et al. Hospital resources available for diagnosing occupational asthma in the UK. Thorax 2005;60(Suppl 2):ii72.

22. Malo JL, Ghezzo H, L'Archeveque J, et al. Is the clinical history a satisfactory means of diagnosing occupational asthma? Am Rev Respir Dis 1991;143:528-32.

23. Ricciardi L, Fedele R, Saitta S, et al. Occupational asthma due to exposure to Iroko wood dust. Ann Allergy Asthma Immunol 2003;91:393-7.

24. Axon EJ, Beach JR, Burge PS. A comparison of some of the characteristics of patients with occupational and non-occupational asthma. Occup Med 1995;45:10911.

25. Cullinan P, Lowson D, Nieuwenhuijsen MJ, et al. Work related symptoms, sensitization, and estimated exposure in workers not previously exposed to flour. Occup Environ Med 1994;51:579-83.

26. Merget R, Caspari C, Kuzler R, et al. The sequence of symptoms, sensitization and bronchial hyperresponsiveness in early occupational asthma due to platinum salts. Int Arch Allergy Immunol 1995;107:406-7.

27. Munoz X, Cruz MJ, Orriols R, et al. Occupational asthma due to persulfate salts: diagnosis and follow-up. Chest 2003;123:2124-9.

28. Houba R, Doekes G, Heederik D. Occupational respiratory allergy in bakery workers: a review of the literature. Am J Ind Med 1998;34:529-46.

29. Houba R, Heederik D, Doekes G. Wheat sensitisation and work-related symptoms in the baking industry are preventable. An epidemiological study. Am J Respir Crit Care Med 1998;158:1499-503.

30. Karjalainen A, Kurppa K, Virtanen $\mathrm{S}$, et al. Incidence of occupational asthma by occupation and industry in Finland. Am J Ind Med 2000;37:451-8.

31. Cortona G, Pisati G, Dellabianca A, et al. Respiratory occupational allergies: the experience of the Hospital Operative Unit of Occupational Medicine in Lombardy from 1990 to 1998. G Ital Med Lav Ergon 2001;23:64-70.

32. Parkes, WR, ed. Occupational lung disorders. 3rd ed. Oxford, UK: ButterworthHeinemann, 1994.

33. Francis $\mathbf{H}$, Prys-Picard C, Fishwick D, et al. Defining and investigating occupational asthma: a consensus approach. Occup Environ Med 2007;64:361-5.

34. Miller MR, Hankinson J, Brusasco V, et al. Standardisation of spirometry. Eur Respir J 2005;26:319-38.

35. Zock JP, Brederode D, Heederik D. Between- and within-observer agreement for expert judgment of peak flow graphs from a working population. J Occup Environ Med 1998;40:969-72.

36. Leroyer C, Perfetti L, Trudeau C, et al. Comparison of serial monitoring of peak expiratory flow and $\mathrm{FEV}_{1}$ in the diagnosis of occupational asthma. Am J Respir Crit Care Med 1998;158:827-32.

37. Malo JL, Cartier A, Ghezzo H, et al. Compliance with peak expiratory flow readings affects the within-and between-reader reproducibility of interpretation of graphs in subjects investigated for occupational asthma. J Allergy Clin Immunol 1996;98:11324.

38. Baldwin DR Gannon P, Bright P, et al. Interpretation of occupational peak flow records: level agreement between expert clinicians and OASYS-2. Thorax 2002; 57:860-4.

39. Huggins V, Anees W, Pantin CFA, et al. Improving the quality of peak flow measurements for the diagnosis of occupational asthma. Occup Med 2005;55:3858.
40. Anees $\mathbf{W}$, Gannon PF, Huggins $V$, et al. Effect of peak expiratory flow data quality on diagnostic sensitivity and specificity in occupational asthma. Eur Respir J 23:730-4.

41. Gannon PF, Newton DT, Belcher J, et al. Development of OASYS-2: a system for the analysis of serial measurement of peak expiratory flow in workers with suspected occupational asthma. Thorax 1996;51:484-9.

42. Agrup G, Belin L, Sjostedt L, et al. Allergy to laboratory animals in laboratory technicians and animal keepers. Br J Ind Med 1986;43:192-8.

43. Cullinan P, Cook A, Gordon $\mathrm{S}$, et al. Allergen exposure, atopy and smoking as determinants of allergy to rats in a cohort of laboratory employees. Eur Respir $J$ 1999;13:1139-43.

44. Venables KM, Tee RD, Hawkins ER, et al. Laboratory animal allergy in a pharmaceutical company. Br J Ind Med 1988;45:660-6.

45. Jeal H, Draper A, Jones M, et al. HLA associations with occupational sensitisation to rat lipocalin allergens: a model for other animal allergies? J Allergy Clin Immunol 2003;111:795-9.

46. Talini D, Benvenuti A, Carrara M, et al. Diagnosis of flour-induced occupational asthma in a cross-sectional study. Respir Med 2002;96:236-43.

47. De Zotti R, Bovenzi M. Prospective study of work-related respiratory symptoms in trainee bakers. Occup Environ Med 2000;57:58-61.

48. Jarvinen KA, Pirila V, Bjorksten $F$, et al. Unsuitability of bakery work for a person with atopy: a study of 234 bakery workers. Ann Allergy 1979;42:192-5.

49. Prichard MG, Ryan G, Musk AW. Wheat flour sensitisation and airways disease in urban bakers. Br J Ind Med 1984;41:450-4.

50. Bernstein IL, Chan-Yeung M, Malo JL, et al. Asthma in the workplace 2005. 2nd ed. Switzerland: Marcel Dekker, 1999.

51. Fishwick D, Fletcher AM, Pickering CA, et al. Respiratory symptoms and dust exposure in Lancashire cotton and man-made fibre mill operatives. Am J Respir Crit Care Med 1994;150:441-7.

52. Burge PS. Occupational asthma in electronics workers caused by colophony fumes: follow-up of affected workers. Thorax 1982;37:348-53.

53. Baur $\mathbf{X}$, Huber $\mathrm{H}$, Degens PO, et al. Relation between occupational asthma case history, bronchial methachlorine challenge, and specific challenge test in patients with suspected occupational asthma. Am J Ind Med 1998;33:114-22.

54. Tarlo SM, Broder I. Outcome of assessment for occupational asthma. Chest 1991;100:329-35.

55. El-Zein M, Malo JL, Infante-Rivard C, et al. Incidence of probable occupational asthma and changes in airway calibre and responsiveness in apprentice welders. Eur Respir J 2003;22:513-8.

56. Moscato G, Dellabianca A, Vinci G, et al. Toluene di-isocyanate-induced asthma: clinical findings and bronchial responsiveness studies in 113 exposed subjects with work-related respiratory symptoms. J Occup Med 1991;33:720-5.

57. Lin FJ, Chen H, Chan-Yeung M. New method for an occupational dust challenge test. Occup Environ Med 1995;52:54-6.

58. Burge PS, O'Brien IM, Harries MG. Peak flow rate records in the diagnosis of occupational asthma due to isocyanates. Thorax 1979;34:317-23.

59. Stenton SC, Avery AJ, Walters EH, et al. Technical note: statistical approaches to the identification of late asthmatic reactions. Eur Respir $J$ 1994;7:806-12.

60. Bello D, Herrick CA, Smith TJ, et al. Skin exposure to isocyanates: reasons for concern. Environ Health Perspect 2007;115:328-35.

61. Bradshaw L, Barber CM, Davies J, et al. Work related asthma symptoms and attitudes to the workplace. Occup Med (Lond) 2007;57:30-5. 